Faculty of Design

2020

Pluriversal design and desire-based design: Desire as the impulse for human flourishing

Leitão, Renata

Suggested citation:

Leitão, Renata (2020) Pluriversal design and desire-based design: Desire as the impulse for human flourishing. In: DRS Pluriversal Design SIG, 4 Jun 2020, New Orleans, USA. Available at http://openresearch.ocadu.ca/id/eprint/3180/

Open Research is a publicly accessible, curated repository for the preservation and dissemination of scholarly and creative output of the OCAD University community. Material in Open Research is open access and made available via the consent of the author and/or rights holder on a non-exclusive basis.

The OCAD University Library is committed to accessibility as outlined in the Ontario Human Rights Code and the Accessibility for Ontarians with Disabilities Act (AODA) and is working to improve accessibility of the Open Research Repository collection. If you require an accessible version of a repository item contact us at repository@ocadu.ca. 


\section{Pluriversal design and desire-based design: desire as the impulse for human flourishing}

LEITAO Renata M.

OCAD University

rleitao@faculty.ocadu.ca

doi: 10.21606/pluriversal.2020.011

A world of many centers is a world where multiple worlds can flourish-where communities outside of the Center can design their own life projects, which reflect who they are, what they value, and who their ancestors had been. This paper argues that a Pluriversal Design - which aims to nurture alternative models of life and ways of worldmaking-is necessarily desire-based, in contrast with conventional needs-based approaches. I make a case for Social Design researchers and practitioners to hone our craft to respond primarily to the communities' desire, in contrast with the current focus on their needs, problems and deficits. I argue that needs-based approaches are conservative, implying the reproduction of a model of life -i.e., what is 'desirable' is supposedly know from the start and/or externally defined. Such approaches do not encourage the creation of new 'possibles'. On the other hand, a desire-based approach is open-ended. In terms of creating a world of many worlds, what is the final result? We do not know yet; we will be doing something that has never been done before. Metaphorically, desire-based social change is about trailblazing with the help of a compass. Desire is the force that we have to engage when our task is to create new ways of shaping the human presence on this planet and new ways of world-making-an openended process towards the Pluriverse.

Desire; needs-centered approaches; Pluriverse; Social Design

\section{Introduction}

What does a world of many centers look like? What is needed to create this reality?

There are many possible answers to those questions, considering many perspectives and positionalities. I speak as a Brazilian/Canadian design practitioner and researcher who has always worked in the Americas. I speak as a woman born and raised in Brazil, who knows what it means to be a Latin

This work is licensed under a Creative Commons Attribution-NonCommercial-Share Alike 4.0 
American woman in North-American academia. And I also speak as a social designer whose research practice evolved in collaborative projects with members of Indigenous communities. Therefore, I speak from a perspective of collaborations between designers and communities outside of the Center of Eurocentric Modernity. And I talk to other designers who are involved or wish to be involved in collaborations with communities outside of the Center, the so-called Global South.

Since the colonial expansion of the 16th century, Europeans (and subsequently North-Americans) have positioned themselves as the Center of the World, creating the belief in a single reality. My perspective is born out of the recognition that communities outside of the Center tend to experience the dark side of Modernity and deal with the destructive legacy of colonialism. I am referring to peoples who were oppressed, deprived of their lands, who experienced slavery, who survived genocide, who are marginalized, and so on.

I am not the only designer involved in collaborations with communities outside of the Center. In the last two decades, emerged the field of Social Design ${ }^{1}$ concerned with complex social problems, which frequently work with local communities. As we designers see ourselves as problem-solvers, there is a tendency to focus on their supposed needs and problems, trying to mitigate suffering and damage. Sometimes I read an entire paper about designers of the Global North working with communities of the Global South with absolutely no mention to their desires, aspirations, visions of the future, sense of identity. Nothing. The communities who receive help have no voice, except to express their problems, needs, and difficulties, and, at last, to say if the solution proposed by the designer is "desirable". So yes, the "solution" might be "desirable", but is it aligned with the desired good life of that community?

In the typical process, the designer starts with a need or problem and look for a desirable solution. I argue that by focusing on needs at the start, and not on desire, we are merely reproducing the world as we know it with a few minor tweaks. These tweaks attempt to reduce damage or perceived deficits in local communities. Nonetheless, reducing damage or deficits is not the same as creating the conditions for flourishing. At best, the tweaks serve as band-aids, and at worse, our focus on designing them can divert our attention from the pursuit of flourishing (Ehrenfeld, 2008).

MODERNITY/COLONIALITY

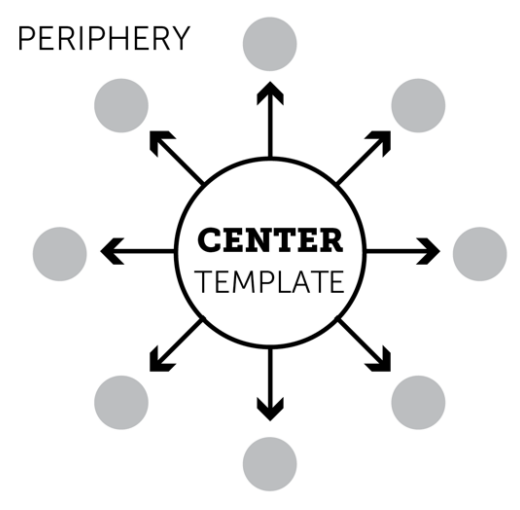

\section{MANY CENTERS}

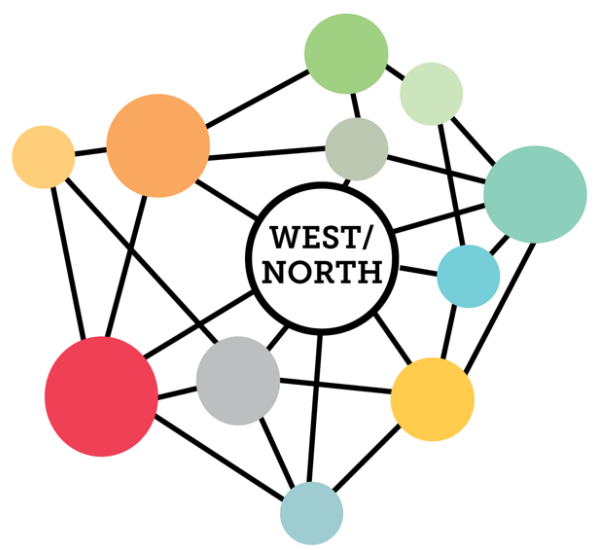

Image 1. A world of only one Center vs. a world of many Centers.

\footnotetext{
${ }^{1}$ Design for Social Innovation, Design for Social Impact, Human-Centered Design, etc. For simplicity's sake, I will use the name of Social Design.
} 
What does a world of many centers look like? A world of many centers is a world where multiple worlds - particularly those that have been oppressed or suppressed by modernity/coloniality - can flourish. When I imagine a world with many centers, I imagine a world where communities outside of the Center of Modernity, become new centers in an interconnected mesh of life. A world in which they can design their own life projects, which reflect who they are, what they value, and who their ancestors had been. Moreover, it is a world where multiple ways of being, thinking, knowing, conceiving reality, and world-making can co-exist. Here we are talking about the Pluriverse, "a world where many worlds fit", a concept suggested by Arturo Escobar (2017) based on a Zapatista dictum. "Talking about the pluriverse entails making visible the existence of multiple worlds" (Escobar 2020: 27). It demands that we consider the alternatives of world-making and the projects proposed by indigenous, local, and subaltern peoples very seriously.

What is necessary to create a world of many centers? To put the communities' desire at the Center of any collaborative process, moving the focus from needs to desire when designing with local communities outside of the Center. I argue that a Pluriversal Design - a form of design that aims to create and nurture alternative ways of world-making and contribute to the construction of other worlds - is necessarily desire-based.

When designing for the Pluriverse, I suggest that we engage with desire as a starting point and then investigate what is needed. Starting from a need involves an entirely different design process than starting from desire. The design theorists Harold Nelson and Erik Stolterman conceptualized the difference between needs-based and desire-based design in their book "The Design Way" (2012). For them, the negative impulse toward action, which arises out of need, "is completely different from the positive impulse born out of the desire to create situations, systems of organizations, or concrete artifacts that enhance our life experiences" (Nelson \& Stolterman 2012, p. 111). They proposed a remarkable desire-based design framework that is, unfortunately, seldom referred to in Social Design frameworks and methods.

People desire to flourish and not just survive. They may not need music or art to survive, but they certainly desire them both. A need is a baseline condition that must be mitigated in order to support and stabilize a given situation. The hungry need to be fed and the cold need to be sheltered - but people desire to be more than "needy" creatures. Desire is the destabilizing trigger for transformational change, which facilitates the emergence of new possibilities and realizations of human "being". (Nelson \& Stolterman 2012, p. 110)

Inspired by their framework ${ }^{2}$, I have considered a Decolonial Desire-based Social Design. Several authors from Other Centers - such as Audre Lorde, Marcos Faustini, Eve Tuck, Paulo Freire, and Amartya Sen had a significant impact on my thinking about the creative force of desire, as I describe in this paper.

\section{Defining desire}

Desire is a word loaded with different meanings for different contexts, disciplines, and traditions of thinking. Several definitions of desire refer to cravings of pleasure, material goods, or recognition associating desire with lust and greed. It may denote a longing, a lack, an assemblage, a psychological

\footnotetext{
${ }^{2}$ I frequently refer to Nelson and Stolterman, Ezio Manzini, and Stuart Walker to show that the ideas I present are not exotic and exterior to design literature. On the contrary, they are an integral part of our discipline. However, they are often disregarded in initiatives of the Global North that impact the Global South.
} 
structure, etc. Eve Tuck even wrote a paper disputing Gilles Deleuze's conceptualization of desire. "I wanted him to say that desire is smart, is wise. Agentic. Though I looked and looked for some indication from him that he recognized desire as insight/ful, the recognition is not there" (Tuck 2010, p. 636). As Tuck, I also understand and experience desire as agentic and wise, but most people do not.

Some conceptions of desire stress the suffering that the feeling of lack brings. However, the sense of lack or incompletion is part and parcel of human experience. Paulo Freire (1970) argues that human beings feel inherently incomplete. He describes men and women "as beings in the process of becoming-as unfinished, uncompleted beings in and with a likewise unfinished reality" (Freire 1970, p. 84). From this feeling of incompletion, lack or dissatisfaction emerges the desire of change that is the trigger to design - i.e., to create things that could change, and ultimately improve, the situation. It is our yearning for completion that makes humans creative beings who create things and act upon the world to transform it. There is no design without desire; it is fundamental to any process of creation and change. Therefore, when Arturo Escobar proposes his notion of autonomous design, "that every community practices the design of itself" $(2017$, p. 5), it must start from each community's desire.

For Nelson and Stolterman, "desire can be understood as the 'force' that provides us with intrinsic guidance and energy" (2012, p. 111). It is important to stress the term 'force', because desire is not a thing or a pre-formed image. Briefly, desire is the force that turns us on. I understand desire as a bodily, corporeal force related to motivation and enjoyment of action. We all recognize the feelings in our bodies: what makes our heart sing, what puts a smile in our lips, what turns us on. Through the action of desire, we recognize what is worth living for, what is valuable for us-instead of following external definitions of what we should value.

\section{Desire as a compass}

Because it honestly indicates what has value to us, desire is a form of guidance and can act as an inner compass. The social innovation program "Agencia de Redes Para Juventude" - created by Marcos Faustini, a theater director born and raised in a favela (slum of Rio de Janeiro, Brazil)-uses the metaphor of desire as a compass quite literally. Working with youth from marginalized backgrounds, one of the program's first exercises is the fabrication of a compass that points to their desire as their North (Lisboa \& Delfino 2014). Participants keep that compass at hand throughout the nine months of the program to guide them towards realizing their initial desire, which can assume different forms. By tapping into a desire, they use creative and drama-based methods to give shape to that desire and, subsequently, to create projects that form the early stages of social enterprises (Peterson 2016).

We harness the powerful bodily energy that is desire when we conceive projects that excite us. This excitement reveals that we have the energy to rise to the challenge and strive to materialize it. Moreover, it shows that we will feel this action as fulfilling. On the other hand, action motivated by need, even when it is absolutely necessary, feels like drudgery-it might be required, but not fulfilling. That is why desire is the only energy that can sustain the long-term and intensive level of engagement necessary to create significant social change.

\section{Desire as Eros}

As I mentioned, desire is not only a mental construction but has a bodily dimension, as the human life force, Eros. Eros directs us to flourishing, as flowers are an expression of Eros in the plant kingdom. And here, I refer to that which Black feminist Audre Lorde (2006) names as the Erotic.

The erotic is a resource within each of us that lies in a deeply female and spiritual plane, firmly rooted in the power of our unexpressed or unrecognized feeling. In order to perpetuate itself, every oppression must corrupt or distort those various sources of power within the culture of the oppressed that can provide energy for change. (Lorde 2006, p. 87) 
Lorde (2006) argues that Western society has vilified, abused and devalued the erotic, relegating it to the bedroom. By doing so, people live outside themselves, following external alien directives instead of the guidance of desire. She explains that we have been raised to fear the "yes" within ourselves, our deepest cravings.

I know first-hand what Lorde is talking about since the erotic cannot be felt secondhand. That deep "yes" that reverberates in my body like an electric charge that moves upwards is what I name as the force of desire. I learned to listen to this electric charge and to trust it as my wisest inner compass. Usually, it manifests itself as a specific and immediate want (I want this) that charges my body with a distinctive energy "yes". The specific want, however, is not the desired destiny, but a pointer of my inner compass, inviting me to walk in that direction.

Beyond the superficial, the considered phrase, "It feels right to me," acknowledges the strength of the erotic into a true knowledge, for what that means is the first and most powerful guiding light toward any understanding. (...) The erotic is the nurturer or nursemaid of all our deepest knowledge. (Lorde 2006, p. 89)

This is a capacity to listen to the body - and its embodied knowledge and wisdom-has been suppressed in a patriarchal society. Patriarchy creates an anti-erotic society that vilifies our deep desires, which are rooted in the feminine plane. And this vilification of desire is not an accident; it is an essential component of the modernist project and capitalism.

\section{The Promised Land of Modernity and The Desirable}

The European model of life (Modernity) was disseminated throughout the globe (via colonialism and globalization), establishing itself as the template of what is good, evolved, and desirable (Hall 1992; Leitão 2018). In the preface of "Encountering Development," Arturo Escobar wrote:

This book grew out of a sense of puzzlement: the fact that for many years the industrialized nations of North America and Europe were supposed to be the indubitable models for the societies of Asia, Africa, and Latin America, the so-called Third World, and that these societies must catch up with the industrialized countries, perhaps even become like them. (2012, p. xlv)

As he remarks, the desirability of this model is never questioned. In the narrative of Modernity, the model of life of Western civilization is the evolutionary destiny of humanity, the one and only and universal pathway towards the future-and following this only pathway constitute "development". In other words, what is universally desirable is a given, Western civilization has already defined. This definition of The Desirable is so ubiquitous that people do not even have a vocabulary to properly refer to other societies and models of life. People refer to societies, countries, and cultures as developed, developing, and underdeveloped, indicating their level of success in following the recipe.

Not only Western civilization has established itself as the desirable model, but spreads promises that people will be better off by adopting its model. The modernist project entails constructing the desire to become modern (or 'developed') as the point of arrival for the entire humanity.

The implicit message is that some kind of future Utopia of sustainable perfection is actually attainable, where our environmental and social problems will be solved through the ingenious application of advanced, super-efficient, non-polluting technologies. (Walker 2010, p. 104) 
This pre-constructed desire, 'the promised land of modernity', is disseminated throughout the planet by the media - images, literature, music, cinema, etc. Designers, particularly graphic designers, are responsible for creating visual representations of what is deemed as desirable.

An essential aspect of the capitalist consumer society is the promise that a product or a service can fulfill your dreams and make you happier (Walker 2010). As Stuart Walker states, modernity "sought to advance human happiness, meaning and fulfillment through industrialization and the consumption of material goods" (2010: 106). The world becomes a supermarket: "life choices tend to considered as choices among marketable goods" (Vezzoli \& Manzini 2008, p. 16). The negative effects of externally pre-defined desires are also visible within the Western culture: environmental crisis, overconsumption, a crisis of meaning, social inequality, and so on.

Repeating, in Western Modern civilization, the desirable is pre-defined externally. Therefore, the active exercise of Desire, of listening to our deep yearnings and engaging with our creative impulse, does not have space in Modern society. Immediate wants, on the other hand, are encouraged with the promise that everything we want or need can be purchased as a product or service. Capitalism involves several activities, such as design and marketing, into the continual creation of new wants, multiplying dissatisfaction, and stimulating overconsumption. This model is intrinsically environmentally and socially unsustainable (Vezzoli \& Manzini 2008). Socially unsustainable because most people on Earth do not have the purchasing power to attain a product-based well-being. Environmentally unsustainable because the Earth simply does not have enough resources to sustain all the inhabitants of the planet in a similar way to of life(Vezzoli \& Manzini 2008). Nonetheless, the promises of Modernity continue to be exported to the rest of the world.

Under the spell of neo-liberalism and the magic of the media promoting it, modernity and modernization, together with democracy, are being sold as a package trip to the promised land of happiness (...) Yet, when people do not buy the package willingly or have other ideas of how economy and society should be organized, they become subject to all kinds of direct and indirect violence. (Mignolo 2007, p. 450)

The hegemonic narrative, however, is not one of violence. On the contrary, it is a narrative of heroism and salvation - the modern hero is there to save the poor people in need (Leitão 2018) - "whether as Christianity, civilization, modernization and development after WWII or market democracy after the fall of the Soviet Union" (Mignolo 2007, p. 463). The devastating consequences of the "salvation" are never included in the hegemonic narrative of the West. When designing with people outside of the Center, Social Design becomes another instrument of "salvation" characterized by a needs-based approach. I do believe designers can contribute to the emergence of the Pluriverse, as long as we put the salvation mindset behind us.

\section{Needs-based vs. Desire-based}

Nelson and Stolterman (2012) argue that a needs-based design assumes that the right outcome is known from the start. In the modern worldview, the ultimate desired outcome is already a given: the Western model of life (but in a hypothetical sustainable version). In collaborations with communities outside of the Center, the current emphasis on their needs (instead of their desires) reveals that the destination is assumedly known, and designers try to help people get there.

Need implies that the desired situation is clearly understood, and that the real state of affairs, which is also clearly understood, is an undesired one. The difference between the desired state and the actual state is framed as the problem. It is also assumed that there is 
no difficulty in determining the needs that must be satisfied in order to realize the desired state. (Nelson \& Stolterman 2012, p. 109-10)

In other words, needs refer to the distance between the current situation and the desired one, and the desired situation is already known. Therefore, a needs-based approach is conservative, implying the reproduction of a model of life, and not encouraging the creation of new possibilities of life, new cultural models, or new forms of world-making. In this frame of mind, we are not even creating the future by design, as we already know the point of arrival. Creativity is limited to the design of technofixes (attempts to fix the 'glitches' of the modern model). Even as we recognize that this model of life is leading us to unsustainability, we keep designing band-aids to the model instead of questioning it and being open to new definitions of the desirable.

On the other hand, a desire-based approach is open-ended, as the transition towards a Pluriverse is an open-ended transition (Escobar 2020). Because Western civilization is a world of only one world, other models of life have been suppressed (and this a story that involves many forms of violence). "It is precisely because other possibilities have been turned into 'impossibles' that we find it so difficult to imagine other realities" (Escobar 2020, p. 3). Escobar (2020) argues that speaking of other possibles and other realities entails a totally different understanding of what change and transformation are.

Consequently, a civilizational transformation will not start from a clear vision of other realities already in place. As Nelson and Stolterman state, in needs-based approaches, people speak of a "vision" as a goal to reach, often as a preformed image, "whereas a desire-based change process leads to a desired outcome but does not start with that outcome neatly in place" (2012, p. 110). They suggest a close relationship between desire and intention-intentionality referring to an expression of aim and direction animated by will. Intention should be understood "as the aiming and subsequent emergence of a desired outcome" (Nelson \& Stolterman 2012, p. 113).

One of the key concepts concerning intention arose in the philosophic discourse of the Middle Ages. At that time, the idea of aim, as in aiming an arrow, became central to the unfolding meaning of intention. That is, that intention is not the target, not the outcome, not the purpose, nor an end state, but is principally the process of choosing or giving direction to effort (Nelson \& Stolterman 2012, p. 113).

In terms of creating new possibilities of life, what is the final result? We do not know yet; we will be doing something that has never been done before. We have to learn to live with uncertainty, knowing that we follow the compass of desire but not yet seeing the final result, which is the ultimate creative (and not conservative) mode. Metaphorically, desire-based social change is about trailblazing with the help of a compass. Therefore desire is the force that we engage when our task is to create new ways of shaping the human presence on this planet and new ways of world-making.

\subsection{Damage-centered vs. desire-based}

Not only designers think in terms of needs, deficits and problems. Social sciences also face similar challenges. In 2009, North-American Indigenous scholar Eve Tuck asked indigenous communities, scholars, and educators to consider the negative long-term impact of what she calls damage-focused research - that is, "research that intends to document peoples' pain and brokenness to hold those in power accountable for their oppression" (Tuck 2009, p. 409). She is particularly concerned with research that invites oppressed peoples to speak, but only speak their pain. She explains that damage-center research "looks to historical exploitation, domination, and colonization to explain contemporary 
brokenness, such as poverty, poor health, and low literacy" (Tuck 2009, p. 413). Damage-centered research is embedded in Social Design methods under the name of empathy ${ }^{3}$.

Tuck (2009) argues that this kind of research unintentionally pathologizes local communities, operating with a flawed theory of change that reinforces a one-dimensional notion of these people as depleted and broken. For her, this "theory of change is flawed because it assumes that it is outsiders, not communities, who hold the power to make changes" (Tuck 2010, p. 638). Social designers tend to portray themselves as agents of social change. While damage-centered narratives end up pathologizing local communities, a needs-centered Social Design focuses on addressing their damages, furthering the disempowering narrative.

Referring to social science and participatory action research (PAR), Tuck (2009) recognizes that there was a time and place for damage-centered approaches. However, in her conversations with Indigenous elders, "they agree that a time for shift has come, that damage-centered narratives are no longer sufficient" (Tuck 2009, p. 415-16). The shift suggested by Tuck is to craft research to capture desire instead of damage.

I submit that a desire-based framework is an antidote to damage-centered research. An antidote stops and counteracts the effects of a poison, and the poison I am referring to here is not the supposed damage of Native communities, urban communities, or other disenfranchised communities but the frameworks that position these communities as damaged. (Tuck 2009, p. 416).

I suggest that Social Design practitioners should hone our craft to respond primarily to the communities' desire. We have considerable work ahead to develop the theoretical foundations and methodology of a desire-based Social Design-as design literature is filled with damage-centered research and needsbased approaches.

\subsection{Reproduction, resistance and desire}

Furthermore, Tuck proposes that desire may interrupt the binary of reproduction of social inequity versus resistance. "Desire is a thirding of the dichotomized categories of reproduction and resistance" (Tuck 2009, p. 419).

As the European model of life (Modernity) was disseminated throughout the globe, it created the uneven relationship center-periphery where the Center becomes the template of what is good, evolved, and desirable. In this worldview, indigenous and non-Western peoples, the Others, were destined to discontinue their traditions, and "become just like us" (Sahlins 1999). But there is a catch, because of structural racism, people from certain ethnicities would never "become one of us", remaining excluded from the hegemonic society. In fact, the "others" are part of the single reality created by ModernityCenter and periphery are integral parts of the same system. In other words, product-based well-being only exists because peoples were exploited and expropriated.

The margins can resist the model of the Center and have resisted for centuries. After five centuries of colonization in America, Indigenous people have not vanished and still have a distinct culture. I can even discuss the possibilities of the Pluriverse because of the peoples who resisted colonization, who resisted assimilation, who resisted development. Any discussion about many worlds can only occur because many people did not desire to become modern and resisted.

\footnotetext{
${ }^{3}$ Empathy, as a human capacity, is fundamental to the work of a designer. However, in many Social Design methods, it refers to a form of damage-centered research.
} 
Resistance is established as an opposition to the center, forming a dichotomy. Even though it is fundamental, it is a reactive force. I believe it is better to consider it as a starting point. The way out of the dichotomy is the creation and recognition of new possibilities and multiple models of life - thus creating the future by design, instead of by default.
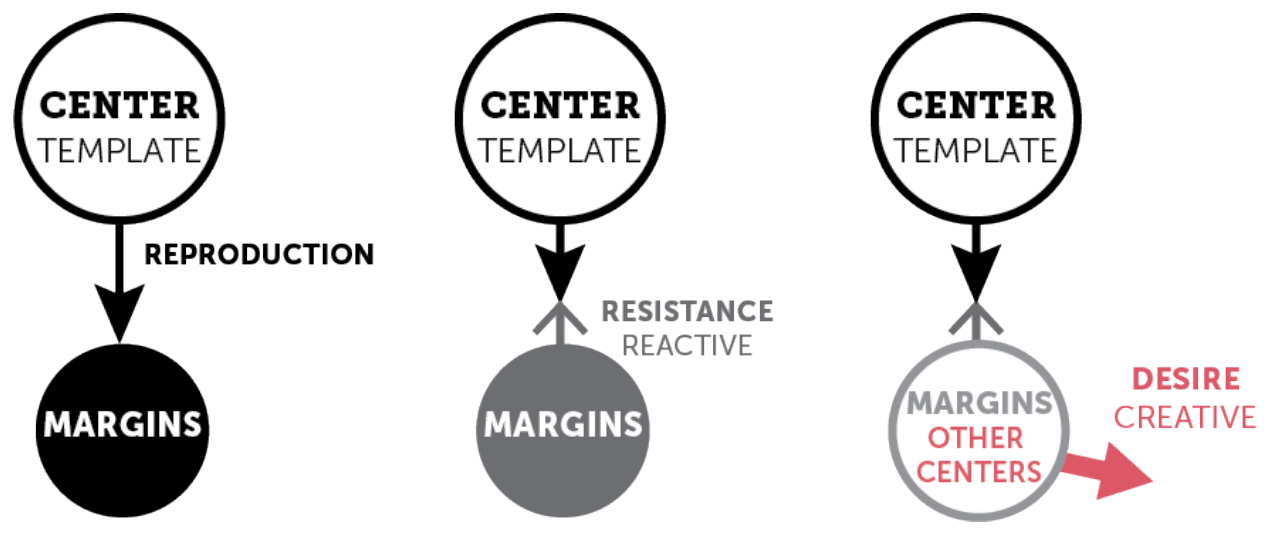

Image 2: The dichotomy reproduction vs. resistance and the third force (desire).

The first two arrows (reproduction and resistance) are aligned with Modernity - one says 'yes' and the other says 'no'. Desire creates a third force, a new alternative. The third arrow can go to multiple directions. Nonetheless, it is important to note that the first two arrows remain active, as long as the "universalizing" processes unleashed by Colonialism and Globalization continue to act.

\subsection{Needs and fulfillment}

A friend listened to my claims for a desire-based approach but argued that there are real baseline needs. "We cannot ignore them; Maslow did not make them up", she stated. Maslow's (1943) hierarchy of human needs is an often-cited reference that has profoundly impacted how people think about human motivation and needs. In his hierarchy, at the base of the pyramid, we have the physiological needs that support homeostasis-i.e., people need food and water to survive. "In addition to physiological needs, Maslow posited needs for safety, belongingness and love, esteem, and self-actualization, in ascend ascending order on the hierarchy" (Koltko-Rivera 2006, p. 303). At the top, we find self-actualization, which refers to the desire for self-fulfillment (Maslow 1943; Koltko-Rivera 2006). Supposedly, people would only pursue the need for self-actualization once the other needs have been met.

It is quite true that man lives by bread alone-when there is no bread. But what happens to man's desires when there is plenty of bread and when his belly is chronically filled?

At once other (and "higher") needs emerge and these, rather than physiological hungers, dominate the organism. And when these in turn are satisfied, again new (and still "higher") needs emerge and so on. This is what we mean by saying that the basic human needs are organized into a hierarchy of relative prepotency. (Maslow 1943, 375)

From his framework, after basic needs are met, "higher" needs can emerge. One could imagine that communities struggling against poverty, violence, and oppression would not be able to (re)design their circumstances and create new forms of life. And yet, as Escobar (2017) argues, it is precisely in those cases - in Indigenous, Afrodescendant, and peasant communities in Latin America - that the examples of life projects and new visions for the future are flourishing. In South-America, where I come from, we see again and again examples of communities struggling with the two lowest levels of Maslow's needs 
create life projects based on their own visions of a "good life" (Barras 2004; Blaser 2019). The creation of visions of the good life refers to the search for fulfillment - the highest order in Maslow's hierarchy.

In needs-based and damage-centered approaches, there is the tendency to focus on the lowest levels of Maslow's hierarchy of human needs - and those levels are usually defined and framed in terms of a material lack or deficiency. It also seems that the empathy proposed by many Social Design methods is particularly tuned in to the basic levels. As a result, we see numerous Social Design projects in which designers "co-design" things - e.g., techno-fixes or services - to respond to lower-level needs.

Again, there is a flawed theory of change behind the focus on addressing baseline needs. People imagine that once the basic level needs are met, people can thrive. Or that once "fixing" the problem that was preventing the community from having their basic needs met, they would do well. Unfortunately, what we often see is disempowerment and creating a cycle of dependency on external resources (Douglas 2004; Eade 2007; Sen 1999; Srinivasan 2012). In this sense, this theory of change is the twin brother of the one that assumes that only outsiders, people from the hegemonic social groups, hold power to make changes (Freire 1968/2005; Tuck 2010).

I am not suggesting that communities outside do not need external resources or having their basic needs met. On the contrary, many of them are struggling with poverty, and many of them need the support of outsiders. Even Bruno Barras-leader of the Yshiro-Ebitoso people of the Paraguayan Chaco, who proposed the concept of 'life-projects' instead of 'development projects' -affirmed:

For us to carry on this life project we need the respectful support of donors and financing institutions from the North. We need them to consult Indigenous leaders and listen to them. (...) I cannot find a stronger way of expressing the urgent need for direct contact between donors and Indigenous leaders to avoid the waste of resources and to remove the mistrust of Indigenous peoples' capacity to manage their own lives. (Barras 2004, p. 51)

I argue that it is detrimental and disempowering to center collaborative relationships on people's basic or material needs. Moreover, I argue that the most basic human need (if we keep Maslow's conceptual framework) is the possibility of self-actualization, of flourishment, of achieving fulfillment. It is this prospect that creates a feeling of dignity.

Economist Amartya Sen (1999) argued that it would be wrong, and have disastrous consequences, to consider that poverty is merely a question of lack of material resources. For him, ultimately, what the poor are denied is their human fulfillment. And as suggested by Nelson and Stolterman (2012), we have to use our desires to understand how we can fulfill our lives and flourish.

\section{The complexity of desire}

Nelson and Stolterman that in our culture "desires are often treated as low-level needs-things that we wish but could live without" (2012, p. 111). Therefore, desire is seen as something superfluous - and examining capitalist society, indeed it is. As people allowed an external definition of value and desire to guide them, this force became superfluous.

When I argue for a desire-based design, I am not suggesting that desires are always good. On the contrary, desires can be very detrimental to individuals and groups of people. I suggest to bring desires to the light and actively engage with them. As Tuck states, "desire flashes out that which has been hidden or what happens behind our backs" (2009, p. 420). Nelson and Stolterman elaborate on the complex and contradictory nature of desire: 
But desires are not all good. To reveal our desires, we have to name them, reflect upon them and examine them. When we examine our desires, we often find the bag fairly well mixed, with both the good and the bad. It is necessary in this process to accept both types of desire. Over time, we learn to discipline the negative desires and live out the positive ones. To differentiate positive desires from negative ones is one of our lifelong tasks as human beings (2012, p. 111).

For them, it is important to become aware of our desires - a process Rosaleen Trainor called 'befriending our desires' (cited in Nelson \& Stolterman 2012, p. 111)-so we can accept their role in our lives and use them as a form of guidance.

Learning to differentiate positive desires from negative ones is not only a lifelong task, but it is one of the most important collective tasks for a civilizational transition. For centuries, we have not nurtured and practiced the capacity to use desire as a source of guidance and energy. Particularly, we do not know how to distinguish an agentic desire from a craving or passive externally defined desire - we do not know how to befriend our desires. On the opposite, in our anti-erotic society, we learned to either mistrust desire and reject it wholesale, or indulge in our wants. What I learned by befriending my desires: an agentic desire is an idea that energizes me. As I learned to recognize that electric charge, I learned that I can trust it.

In the Brazilian program "Agencia de Redes Para Juventude" [Agencia], participants are led to befriend their desires as the first step to develop agency. As already mentioned, participants build a compass from their desire that will guide them throughout the process. Giving visible shape to their desires and naming them allows the participants to refine them in order to generate projects that might have a positive impact on their communities (Lisboa \& Delfino 2014). Lisboa and Delfino make a case for using specifically the term 'desire' and not dreams or aspirations. They affirm that the realization of dreams and aspirations can be very distant from the experience of youth from the favelas. Desire, on the other, being more immediate to their experience, is an invitation to action. The term desire adds more emphasis on what someone indeed wants to do, create, conceive and make (Lisboa \& Delfino 2014).

\subsection{Creating desire-based frameworks and methods}

Tuck suggests that desire-based frameworks are "concerned with understanding complexity, contradiction, and the self-determination of lived lives (2009, p. 416). Therefore, we are not talking about realizing an idea that we deem as desirable straight away. First, we have to examine, name, and visualize our desires honestly. We can use visual methods, crafts, or drama techniques to allow participants to reflect upon, discuss the contradictions with other people, and understand the direction towards which their desires are gesturing. We have to see the immediate wants that are involved and start to distinguish craves and passive (externally defined) desires from the agentic desires. The distinction is not by any means clear; sometimes craves and wants are gesturing towards a deeper impulse. Therefore, working with desires embraces complexity and contradiction.

It is important to mention that, in design, sometimes people use the expression "creating desirable futures" or "visualizing desirable futures". Here we are not talking about engaging directly with desire, but we are creating aspirational horizons. Dreams, visions and aspirations are accepted in modern society, and even encouraged. Desires, on the other hand, are vilified.

When we work with dreams and aspirations, we can keep a needs-based approach, in which the desired final state is pre-defined or defined at the start of the process. A desire-based approach embraces openended exploration. To create new possible and new futures-that which we do not know yet- we have to combine aspirations, dreams, and vision with the force of desire. What is the difference? We can have a dream and never act on it. We can create a desirable vision and do not know how to give the first 
step, and then the second step. Desires, however, are agentic, as Tuck (2010) suggests. For Lisboa and Delfino, they are an invitation to action. Desire refers to be ready to act, awakened, excited, energized, eager. That is the force that makes real change happen.

Recognizing the power of the erotic within our lives can give us the energy to pursue genuine change within our world, rather than merely settling for a shift of characters in the same weary drama. (Lorde 2006, p. 91).

\section{Conclusion}

This paper made a case for Social Design researchers and practitioners to hone our craft to respond primarily to the communities' desire. If a world of many centers is a world where multiple worlds can flourish, Pluriversal Design is a form of design that aims to nurture alternative ways of world-making, and to support to the construction of other worlds by people outside of the Center. In this endeavor, I argue that Pluriversal Design is necessarily desire-based.

What is needed to create a world of many centers? A concentrated effort to establish the theoretical foundations, methodology and methods of a desire-based Social Design.

\section{References}

Barras, B. (2004). Life Projects: Development Our Way. In M. Blaser, H. A. Feit, \& G. McRae (Eds.), In the Way of Development: Indigenous Peoples, Life Projects and Globalization (pp. 47-51). London: Zed Books.

Blaser, M. (2019). Life Projects. In A. Kothari, A.Salleh, A. Escobar, F. Demaria \& A. Acosta (Eds.), Pluriverse: A Postdevelopment Dictionary (pp. 234-236). New Delhi: Tulika Books.

Douglas, M. (2004). Traditional Culture - Let's Hear No More About It. In V. Rao \& M. Walton (Eds.), Culture and Public Action. Palo Alto: Stanford University Press.

Eade, D. (2007). Capacity building: who builds whose capacity? Development in Practice, 17(4-5), 630-639.

Ehrenfeld, J. R. (2008). Sustainability by Design: a subversive strategy for transforming our consumer Culture. New Haven: Yale University Press.

Escobar, A. (2012). Encountering Development: The Making and Unmaking of the Third World. Princeton: Princeton University Press.

Escobar, A. (2017). Designs for the Pluriverse: Radical Interdependence, Autonomy, and the Making of Worlds. Durham: Duke University Press.

Escobar, A. (2020). Pluriversal Politics: The Real and the Possible. Duke University Press.

Freire, P. (1970). Pedagogy of the oppressed. New York: Continuum.

Koltko-Rivera, M. E. (2006). Rediscovering the Later Version of Maslow's Hierarchy of Needs: Self-Transcendence and Opportunities for Theory, Research, and Unification. Review of General Psychology, 10 (4), 302-317.

Leitão, R. M. (2018). Recognizing and overcoming the myths of modernity. DRS 2018 Design Research Society International Conference Proceedings, June 25-28, Limerick.

Lisboa, A. P. \& Delfino, V. (2015). Dicionário - Agência de Redes Para Juventude. Rio de Janeiro: Avenida Brasil.

Lorde, A. (2006). Uses of the erotic: The erotic as power. In K. Lovaas \& M. M. Jenkins, Sexualities and Communication in Everyday Life: A Reader (pp. 87-91). Thousand Oaks: SAGE.

Manzini, E. (2015). Design When Everybody Designs: An Introduction to Design for Social Innovation. Cambridge, London: MIT Press.

Maslow, A. H. (1943). A theory of human motivation. Psychological Review, 50, 370-396. 
Maslow, A. H. (1954). The instinctoid nature of basic needs. Journal of Personality, 22(3), 326-347.

Nelson, H. G., \& Stolterman, E. (2012). The Design Way: Intentional Change in an Unpredictable World (Second ed.). Cambridge, London: The MIT Press.

Peterson, M. (2016). From box-ticking to social impact for arts-based interventions. The Social Innovation

Partnership (TSIP). Retrieved from http://tsip.co.uk/news/2016/from-box-ticking-to-social-impact-for-artsbased-interventions

Quijano, A. (2007). Coloniality and Modernity/Rationality. Cultural Studies, 21(2-3), 168-178.

Sen, A. (1999). Development as Freedom. Oxford: Oxford University Press.

Srinivasan, R. (2012). Rethinking Digital Cultures and Divides: The Case for Reflective Media. The Information Society, 28(1), 24-36.

Tuck, E. (2009). Suspending Damage: A Letter to Communities. Harvard Educational Review, 79(3), $409-427$.

Tuck, E. (2010). Breaking up with Deleuze: Desire and valuing the irreconcilable. International Journal of Qualitative Studies in Education, 23(5), 635-650.

Vezzoli, C. A., \& Manzini, E. (2008). Design and Innovation for Sustainability. London: Springer.

Walker, S. (2010). Sermons in stones: argument and artefact for sustainability. Les ateliers de l'éthique, 5(2), 101116.

About the Author:

Renata M. Leitão, Ph.D. am a Brazilian/Canadian social change-focused design researcher. I am co-chair of the DRS Pluriversal Design SIG. Most of my research practice evolved in close collaboration with Indigenous cultural stewards. Notably, in my doctoral research, I conducted a five-year (2012-2017) Participatory Action Research project in collaboration with members of the Atikamekw Nation (Quebec, Canada). My main research interest is in how the practice of design might support the self-determination of Indigenous, Afrodescendant and marginalized communities. 